\title{
The wear mechanisms of reaction bonded silicon carbide under abrasive polishing and slurry jet impact conditions
}

\author{
T. Nguyen ${ }^{1}$, D. Liu ${ }^{1,2}$, K. Thongkaew ${ }^{1}, \mathrm{H} \mathrm{Li}^{3}$, Huan $\mathrm{Qi}^{4}$, and J. Wang ${ }^{1, *}$ \\ ${ }^{1}$ School of Mechanical and Manufacturing Engineering, UNSW Sydney, NSW 2052, \\ Australia \\ ${ }^{2}$ Center for Advanced Jet Engineering Technologies (CaJET), Key Laboratory of High- \\ efficiency and Clean Mechanical Manufacture (Ministry of Education), School of Mechanical \\ Engineering, Shandong University, Jinan 250061, China \\ ${ }^{3}$ Griffith School of Engineering, Griffith University, Nathan QLD 4111, Australia \\ ${ }^{4}$ School of Mechanical Engineering, Zhejiang University of Technology, Hangzhou, China
}

\begin{abstract}
A study of the wear mechanism on a reaction bonded silicon carbide (RB-SiC) subjected to fixed abrasive polishing and loose abrasive waterjet (AWJ) impact conditions is presented. It is found that the wear of the material is characterised by different mechanisms in its silicon and silicon carbide constituents. The surface polished by diamond abrasives appears with brittle fractures on the silicon carbide phase, while the silicon phase is found to be plastically deformed and embedded onto the surface of the fractured silicon carbide. Submicrometre surface finish can be obtained by polishing using silicon carbide abrasives, and the process is initiated through the penetration of abrasive tips into the softer silicon matrix. Since the progressive wear flattens the tips of abrasives, the penetration depth of abrasives into the material gradually decreases. When the penetration depth is below a critical value, ductile material removal mode becomes dominant in the removal process. When abrasives that are softer than the silicon carbide grains are sufficiently introduced onto the material surface by a slurry jet, wear can occur even at a pressure below the critical value for phase transformation of the silicon constituent. Wear takes place mainly through weakening the Si bond by erosion and wedging, which eventually releases the $\mathrm{SiC}$ grain from the material structure. It is feasible to use a relatively low-pressure alumina slurry jet to machine RB-SiC without causing any surface damage and the processed surface quality depends mainly on the material structure.
\end{abstract}

Keywords: Abrasive Wear; Reaction Bonded Silicon Carbide; Phase Transformation; Particle Hardness; Slurry Jet

*Corresponding author: Tel: +61-2-93855784, E-mail: jun.wang@unsw.edu.au (J. Wang). 


\section{Introduction}

RB-SiC is a composite made from a mixture of silicon carbide (SiC) grains which are chemically bonded together through the infiltration of molten silicon (Si) [1, 2]. It has an excellent property of light weight, good chemical inertness, high stiffness, high hardness, high thermal conductivity and low thermal expansion. As a result, it has become a promising material in various applications under severe thermal and loading conditions. A particular application of RB-SiC is for the construction of optical devices used in the space where the environment is thermally harsh and cryogenic, and light weight is essential. For example, a $650 \mathrm{~mm}$ diameter optical space mirror has been reported by Suyama et al. [3] while a $3.5 \mathrm{~m}$ diameter reflector has been used in the Space Infrared Telescope for Cosmology and Astrophysics (SPICA) [4].

On the other hand, RB-SiC is typically considered as a difficult-to-machine material. Polishing of RB-SiC to the mirror finish is challenging and time consuming. When polishing a surface, an abrasive first needs to engage into the material surface by its edges. Following the motion of the engaged particle that rolls over its axis and glides over the material, a micro/nano-groove is generated on the surface. A polished surface is formed by the assemblage of numerous micro/nano-grooves created by the abrasives. To engage with and process the hard SiC grains, it requires the abrasives with a higher hardness, as well as a higher wear resistance so that their sharpness can be retained during the process. Because of the high brittleness of the SiC grains, the pressure applied on it by the sharp abrasive edges can easily cause cracks along the grooves created. A research on single-point cutting on a single phased SiC workpiece using diamond tool shows that the possibility of ductile machining mode can only occur under certain conditions of small feed rate, negative tool rake angle and when the depth of cut is less than $500 \mathrm{~nm}$ [5]. The selection of process 
parameters to avoid crack formation inevitably results in low material removal rates and long processing time. Moreover, the difficulty is not only caused by the hardness and brittleness of the $\mathrm{SiC}$ constituent, but also due to the non-uniformity of the $\mathrm{RB}-\mathrm{SiC}$ structure. For a single phase material whose response to stresses is uniformly distributed over its structure, the grooves created are continuous, which allows the polished surface to be controlled uniformly. However, RB-SiC is a two-phase material consisting of a $\mathrm{Si}$ matrix surrounding the $\mathrm{SiC}$ grains, so that its responses to stresses are distinctively different. It is noted that the $\mathrm{SiC}$ grains are brittle and experience no phase transition during a polishing process, whereas the Si matrix is not only softer than the $\mathrm{SiC}$ grains, but also transformable by stresses to an amorphous phase which is plastic deformable under stresses [6]. An abrasive that can engage into the Si matrix may engage at a lower depth or not engaged at all with the hard SiC grains. On the other hand, when penetrating deeply into the SiC grains, an abrasive may initiate a sufficient stress to induce phase transformation of the Si matrix. As a result, the SiC phase is removed in the brittle mode with the appearance of detrimental cracks. At the same time, the Si matrix may be processed smoothly in the ductile mode with plastic deformation. The motion of an abrasive to form a micro/nano-groove therefore can be disrupted when passing through the two constituents, so that achieving a high integrity surface is difficult. The attempts to polish RB-SiC have considered mainly the capability of the abrasives that can process the hard SiC phase. There is little consideration about the different responses to stresses by the two material constituents.

There have been some attempts to soften the material surface by thermal-chemically converting its structure to softer $\mathrm{SiO}_{2}$ which is then removed by polishing with ceria slurry [7]. Since the chemical inertness and thermal stability of the material, the converting process essentially requires a high heat source intensifying a small processing area. The heat sources 
used in the attempts include the use of plasma in cooperating with a mixture of $\mathrm{He} / \mathrm{CF}_{4} / \mathrm{O}_{2}$ [7], or plasma with the process gas of helium based water vapour [8]. Because the oxidation rate of $\mathrm{Si}$ is higher than that of $\mathrm{SiC}$, selecting the parameters of oxidation process to minimise the difference in oxidation rate is difficult. An improper control of the oxidation process can lead to a thicker layer of $\mathrm{SiO}_{2}$ resulted from the faster chemically reacted constituent. This in turn results in a residual of soft $\mathrm{SiO}_{2}$ layer on the post polishing surface, or a rough surface obtained if over-polishing. Although the achievement of ultra-smooth surfaces has been reported, the nonuniformity of heat flux applied when processing a large material area may encounter a problem with the flatness of the processed surface. This problem together with the long processing time, as mentioned in [9], would hinder the method to be widely used in the processing of large components. There was another attempt to promote the oxidation using anodic method [9]. The work stated that it was possible to control the oxidation rate of the hard phase SiC to be higher than that of Si. Since the softer phase Si can be polished using ceria slurry, the difference in the oxidation rate could be compensated through the polishing process. The report showed an improvement in material removal rate. However, the study was preliminary and there has been yet a report on the surface finish obtained.

An important factor that affects the quality of the polished surfaces of RB-SiC is the method to introduce abrasives onto the material surface, as this can alter the material removal mechanism. Beside the conventional methods such as grinding or lapping where the abrasive engaging depth and pressure can be somewhat controlled reasonably, there have been many attempts using AWJ to polish hard materials [10]. Using a suspension abrasive-liquid jet, brittle materials such as glass [11] and silicon nitride [12] can be polished smoothly in the ductile mode without the formation of cracks that are often found when conventional 
methods are used. However, no reported study has been found about using this method to process the RB-SiC material.

In this study, the material removal mechanisms of $\mathrm{RB}-\mathrm{SiC}$ and the resulting surface quality when subjected to the action of abrasives are investigated. Abrasives of different hardness ranging from harder, equal to and softer than that of the hard $\mathrm{SiC}$ phase are considered and applied in different modes, including fixed particle polishing and suspension jet impacting.

\section{Material and Experiment}

Fig. 1 shows the microstructure of the specimen. It consisted of $\mathrm{SiC}$ grains of approximate 35 $\mu \mathrm{m}$ in size surrounded by a Si matrix. Since the volume of impurities in the material is negligible as compared with the two major constituents of $\mathrm{Si}$ and $\mathrm{SiC}$ [2] and there is no porosity observed within the microstructure, the volume fraction of $\mathrm{Si}, C_{S i}$, can be calculated using

$$
C_{S i}=\frac{V_{S i}}{V}=\frac{\frac{m}{V}-\rho_{S i C}}{\rho_{S i}-\rho_{S i C}}
$$

where $V_{S i}$ is the volume of Si component contained in the sample that has the measured mass, $m$ and volume $V ; \rho_{\mathrm{SiC}}$ and $\rho_{\mathrm{Si}}$ are the density of the $\mathrm{SiC}$ and $\mathrm{Si}$ components, respectively. For the sample considered in this study, $C_{S i} \approx 21.5 \%$. The other properties of $\mathrm{RB} \mathrm{SiC}$ are shown in Table 1. 


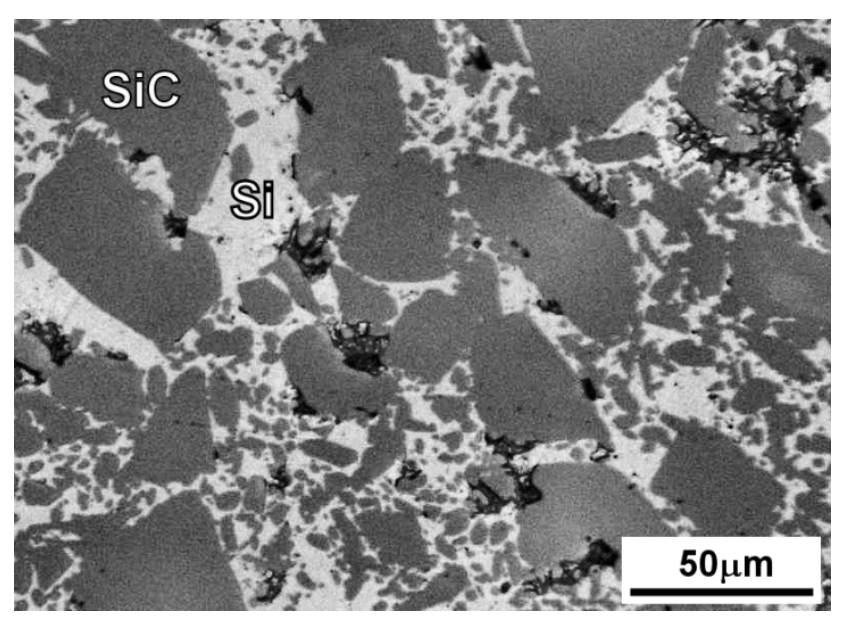

Fig. 1. Microstructure of RB-SiC material.

Table 1. Physical properties of materials.

\begin{tabular}{lllll}
\hline \multirow{2}{*}{ Material } & \multicolumn{2}{c}{ Abrasive } & \multicolumn{3}{l}{ Target material } & \\
& Alumina & SiC & RB-SiC & Si \\
\hline Micro hardness $(\mathrm{GPa})$ & 20.45 & 24.53 & $13.12(\mathrm{Si}), 24.53(\mathrm{SiC})[13]$ & 13.12 \\
Density $\left(\times 10^{3} \mathrm{kgm}^{-3}\right)$ & $3.95^{*}$ & $3.21^{*}$ & 3.05 & 2.33 \\
Toughness $\left(\mathrm{MPam}^{1 / 2}\right)$ & 3.5 & & $3.045[14]$ & $0.84[15]$ \\
\hline
\end{tabular}

* measured in dry powder form.

Two methods were used to deliver the abrasives onto the processing surface, i.e. fixed particle polishing (or grinding) and slurry jet impact.

The polishing method was used to control the flatness of the samples. This ensured that the abrasives could act on both of the two material constituents at a same depth of cut and load. RB-SiC specimen in a disk form with the diameter of 40mm was used for this purpose and surface topology of a specimen is shown in Fig. 2. The average roughness in central-line average, $R_{a}$, was about $14 \mu \mathrm{m}$, with a large waviness in the average magnitude of about 47.9 $\mu \mathrm{m}$ in the peak-to-valley height. 

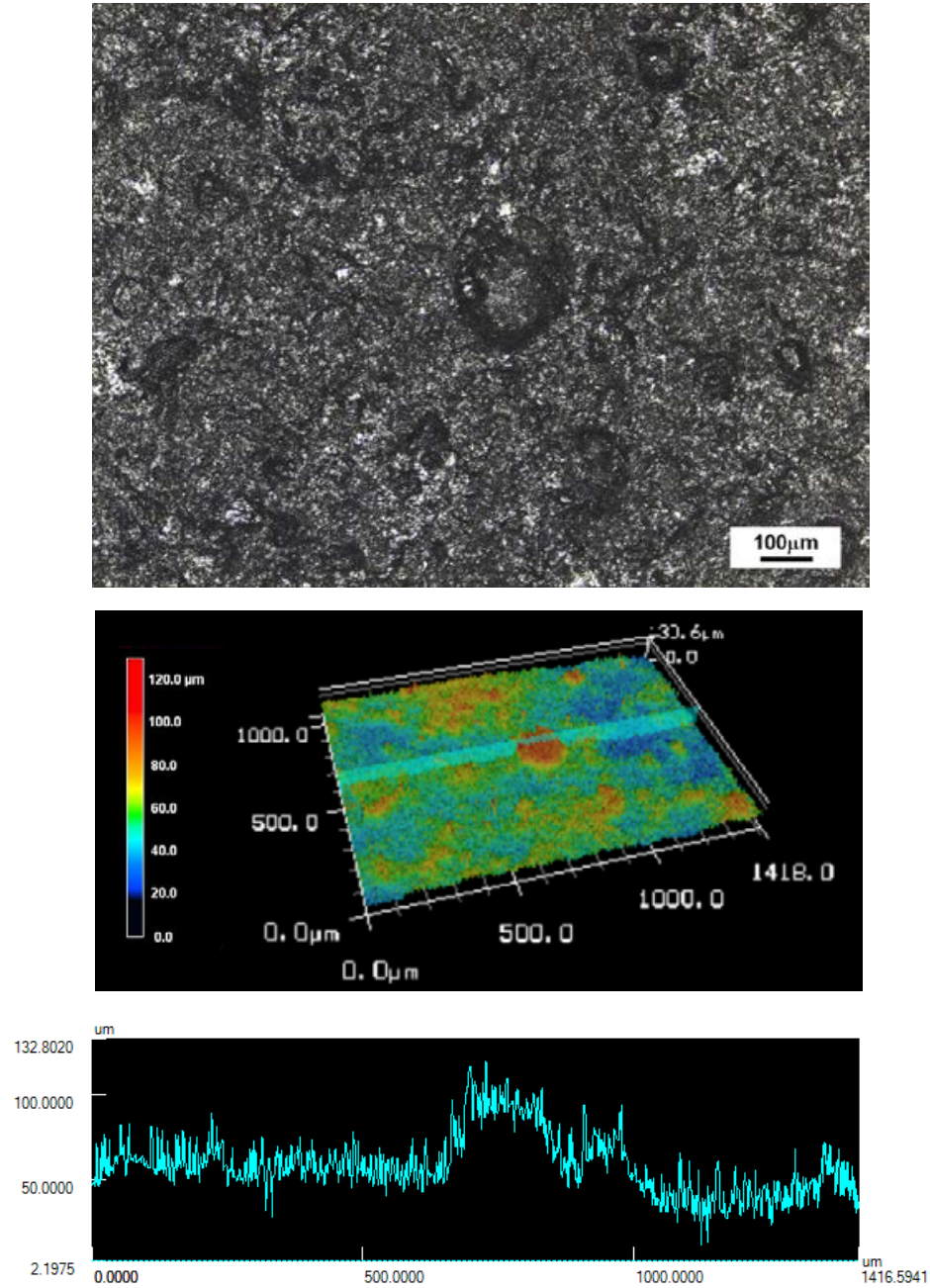

Fig. 2. Topology of a raw specimen surface.

The polishing process was conducted on a Struers-TegraForce-1 polishing machine operating at a $20 \mathrm{~N}$ loading force and a $30 \mathrm{rpm}$ rotating speed with a $200 \mathrm{~mm}$ polishing disk. The sample surface was placed against the abrasive disk and moved randomly within a retainer. With this process the linear polishing speed on each part of the sample was unfortunately varied randomly. Fresh water was used to remove any possible chips from the process. Two types of abrasives, diamond and SiC, were used; they were a Struers MD-Piano 220 diamond disk and a SiC 220 paper with the same diameter of $200 \mathrm{~mm}$. These two abrasives had the same size of $65 \mu \mathrm{m}$ (220 mesh) which was larger than the average size of the SiC constituent in the specimens. The polishing time on the diamond disk was 3 minutes, and on the SiC 
paper it included 5, 10 and 15 minutes without changing the polishing disk within each process.

In the second method of supplying abrasives, an AWJ created from a slurry jet system was used. The system as shown in Fig. 3 consisted of an air driven Haskel fluid pump to pressurise the water to a desired pressure. The pressurised water was delivered into a vessel, inside which there was a bladder containing premixed slurry and some (10 to 15) $13 \mathrm{~mm}$ diameter glass pebbles to help stir the slurry with a shaker. In this way, the premixed slurry was isolated from the pressurised water. Prior to the test, the vessel was placed on a shaker vibrating at about $1 \mathrm{~Hz}$ for about five minutes, so that with the aid of pebbles stirring inside the bladder, it allowed the slurry to be mixed properly. The test was then conducted immediately to prevent the settling of abrasive particles. Under the applied pressure, the slurry was squeezed through a nozzle tube, assembled as shown in Fig. 4. The nozzle tube was made of Zirconium Oxide $\left(\mathrm{ZrO}_{2}\right)$ ceramic with the nominal inner diameter, $d=0.125$ $\mathrm{mm}$ and length, $l=10 \mathrm{~mm}$. The use of highly wear resistant Zirconium Oxide allowed the flow of slurry through the nozzle at a low friction [16]. The large nozzle aspect ratio $(l / d>$ 50) was for effective isolation of the jet flow from the far upstream disturbance at the nozzle inlet [17], to ensure that for the given setup of standoff distance (distance from the nozzle tube outlet to the surface impacted), the diameter of impact area was maintained as the same as the nozzle diameter [18]. Prior to and after each test, the nozzle diameter was inspected to ensure that its dimension did not exceed $0.150 \mathrm{~mm}$. The nozzle assembly was mounted on an enclosed XYZ controller with the control resolution of $\pm 0.01 \mathrm{~mm}$. The enclosure was to prevent the dispersion of mist into the laboratory atmosphere. The enclosure had a clear Perspex window for observation. The nozzle was placed perpendicularly to the sample surface with the standoff distance of $3.5 \mathrm{~mm}$. This small standoff distance was set to 
minimise the effect of stagnation in the impact zone [11], and avoid the nozzle blockage due to backwash.

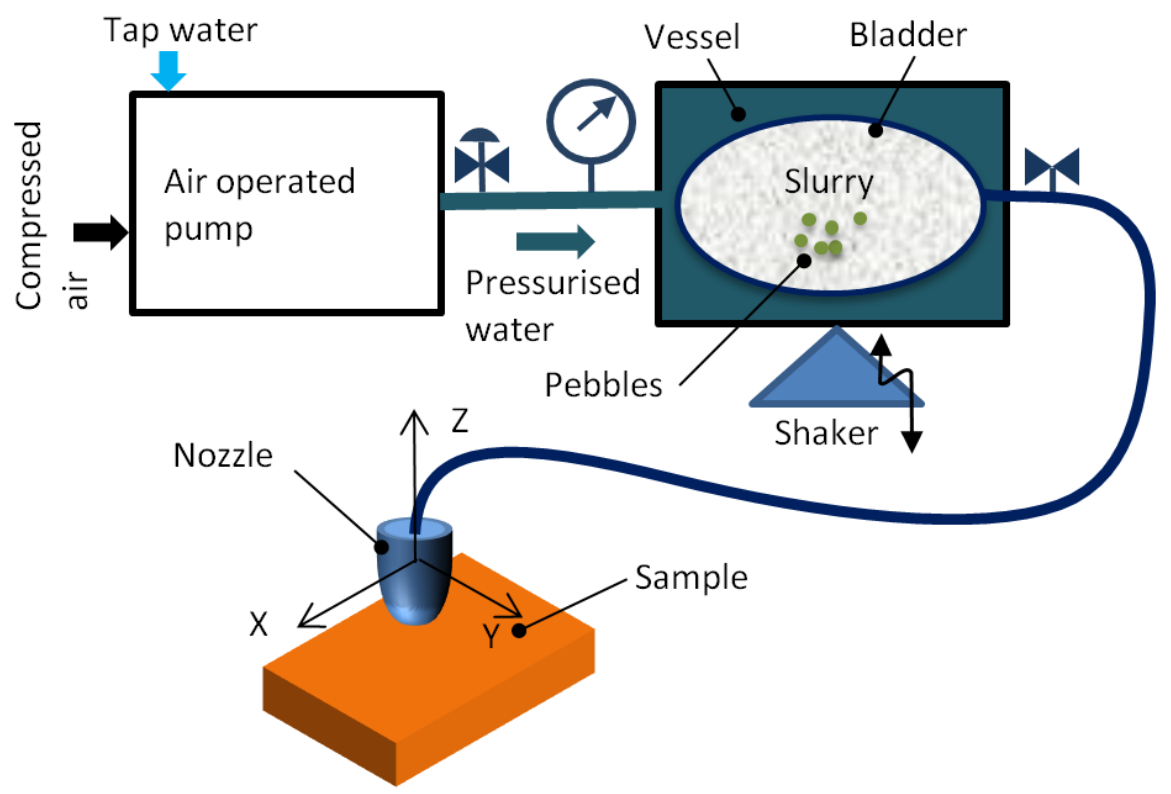

Fig. 3. Schematic of the slurry jet system.

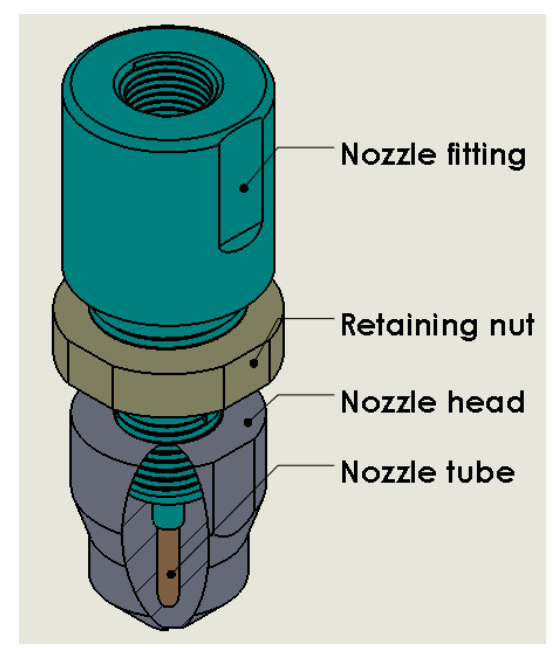

Fig. 4. Broken-out sectional view of nozzle assembly.

To compare the effect of abrasive hardness on the material removal process, two different types of abrasives were used in the premixed slurry, i.e. alumina and $\mathrm{SiC}$ whose material properties are shown in Table 1 . The alumina abrasives have the Mohs hardness of 9 (HV $\approx$ 
20.45 GPa [19]) which is higher than that of the Si constituent but lower than that of the SiC constituent of target material. Both types of abrasives had a same size of $25 \mu \mathrm{m}$ and they were mixed in the slurry with a concentration of $15 \%$ by mass. The RB-SiC samples used in this slurry jet test had a surface roughness $\mathrm{Ra}=0.65 \mu \mathrm{m}$. For comparison, another material of a single-phased structure, silica (111) wafer, was tested and its typical properties are also given in Table 1.

Before any inspection and measurement were taken with a Keyence VK-X200 laser microscope, the processed surfaces were placed into an ultrasonic vibration cleaner to remove any residual debris, and then cleaned using acetone and left until complete acetone evaporation from the surface.

\section{Results and Discussion}

\subsection{Wear mechanisms during diamond disk polishing}

Fig. 5 shows the surface processed by diamond polishing. After 3 minutes, the large waviness on the sample has been removed with the peak-to-valley height reduced to less than $6 \mu \mathrm{m}$, and the average surface roughness, $R_{a}=1.79 \mu \mathrm{m}$. The surface appears with irregular pits resulted from the large-scaled fractures of the SiC grains. It is in a clear contrast with the $\mathrm{Si}$ phase where a number of deep and parallel grooves aligned with the abrasive motion are found. The flow of material indicates that it was processed through the ductile removal mode. The portion of area taken by Si (white colour) appears larger than that of the pre-processed sample (Fig. 2), implying that there was an embedment of the plastically deformed Si chips over the surface of the fractured SiC grains. The observation of plastic behaviour of the Si phase is consistent with that obtained from another research when a single diamond cutting tool was used for turning RB-SiC [20]. The inspection by Raman spectroscopy on the 
machined surface revealed an amorphisation in the Si phase which consequently was deformed during the turning process.

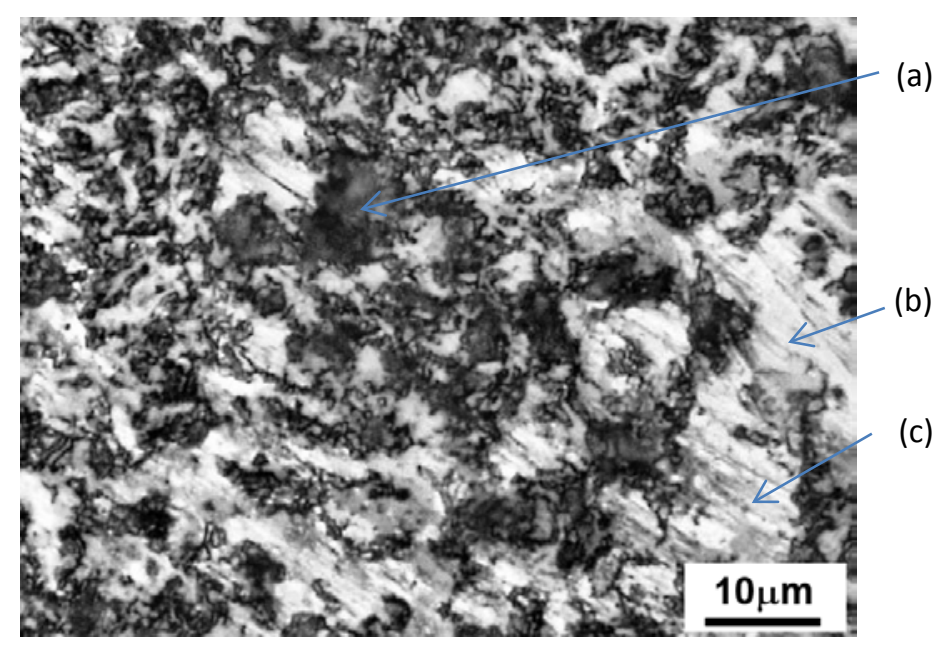

Fig. 5. Surface polished by $65 \mu \mathrm{m}$ diamond abrasives (processing conditions: $200 \mathrm{~mm}$ diameter diamond disk, $30 \mathrm{rpm}$ rotational speed, $20 \mathrm{~N}$ loading force and 3 minutes processing time): (a) brittle fractured pit on a SiC grain, (b) embedment of plastically deformed Si, and (c) grooves.

(a)

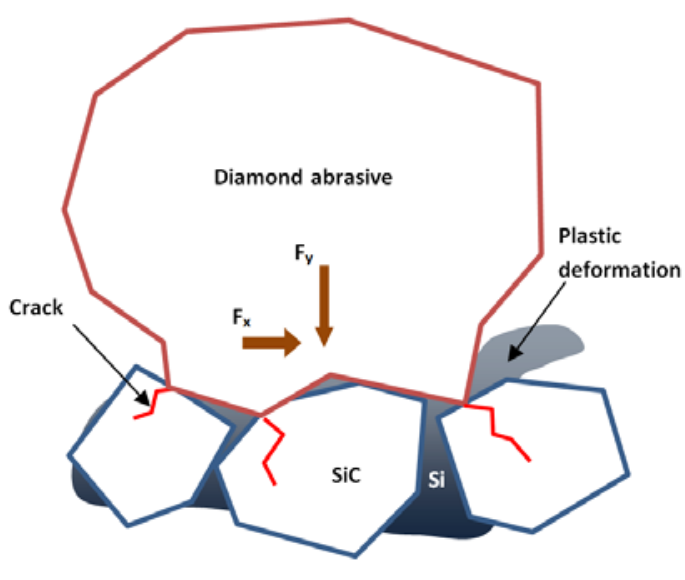

(b)

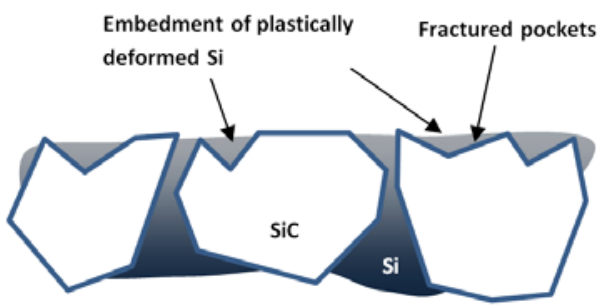

Fig. 6. Wear mechanism of RB-SiC by diamond abrasives: (a) Cracks formed on SiC grains and plastic deformation on Si matrix; and (b) Embedment of plastically deformed Si in the fractured pockets of SiC grains. 
Fig. 6 illustrates the wear process. SiC is known as a very brittle material, and its phase transformation occurs only at an extremely high pressure above $95 \mathrm{GPa}$ [21]. Because of this high brittleness, when a large load transferred from a diamond abrasive into a SiC grain, deep cracks can be generated and propagated along the grain cleavage. Large fragments may also be formed and removed from the grains, leaving the surface with large pits. However, it is different to the dominance of brittle material removal mode which often occurs on the surface of single phase $\mathrm{SiC}$ material processed by grinding [22]. There was a plastic deformation within the Si phase. Stresses play a major role in the plastic response of the Si phase in which amorphous transformation can be initiated, even at extremely low temperature of liquid nitrogen boiling point $\left(-195^{\circ} \mathrm{C}\right)$ [23]. Some previous studies show that plastic deformation of amorphously transformed Si can be initiated when indented at hydrostatic pressure greater than 11-13 GPa [6, 24]. Since diamond abrasives have a higher wear resistance than SiC, their sharpness was retained during the process. The retained sharpness allowed the edges of diamond abrasives to engage into the sample material with small contact areas, thus allowing sufficient stresses to be developed to cause a plastic deformation on the Si phase. At the same time, since the diamond abrasives were relatively larger than the SiC grains (65 $\mu \mathrm{m}$ vs $35 \mu \mathrm{m}$ $\mathrm{SiC})$, it allowed a portion of the amorphous Si to be removed from its matrix. The removed amorphous Si was accumulated and compressed into the spaces between the diamond abrasives and the processed sample surface. During the process, the deformed $\mathrm{Si}$ is transferred and deposited on the available pits formed as a result of the fractured SiC grains.

It is evident that diamond abrasives are powerful for processing the RB-SiC material. However, it is difficult to control the surface defects caused by brittle fractures induced by the process. 


\subsection{Wear mechanisms during SiC disk polishing}

Fig. 7 shows the surface processed in $\mathrm{SiC}$ polishing. In the current engineering practice, a hardness ratio of 5:1 between the cutting tool and the workpiece is normally recommended, and the ratio lower than 2:1 can cause the tool facing tremendous cutting resistance [25]. In this work regardless the hardness of abrasives, wear in fact took place, though it use was not effective as diamond abrasives in the removal of material. Although using the same abrasive size and processing at a longer time (15 minutes vs 3 minutes using diamond abrasives), only the portion that exposed on the peaks on the surface was removed. Nevertheless, a good surface quality was obtained on the peak area, as shown in Fig. 8, and the surface roughness was reduced as the processing time increased. For example, the surface roughness ( $\mathrm{Ra})$ decreased from $0.79 \mu \mathrm{m}$ (Fig. 8(a)) to $0.60 \mu \mathrm{m}$ (Fig. 8(b)) when the processing time was increased from 5 to 10 minutes. However, a further increase of the processing time to 15 minutes did not cause any significant improvement on the surface roughness, i.e. $R_{a}=0.57$ $\mu m$ (Fig. 8(c)).

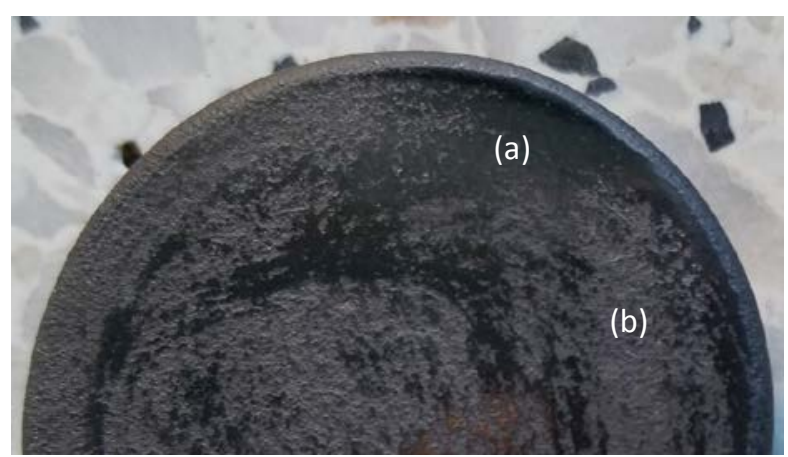

Fig. 7. Surface polished by $65 \mu \mathrm{m} \mathrm{SiC}$ abrasives after 15 minutes (processing conditions: 200 mm diameter polishing disk, $30 \mathrm{rpm}$ rotational speed rpm and $20 \mathrm{~N}$ loading force): (a) processed area, and (b) non-processed area. 

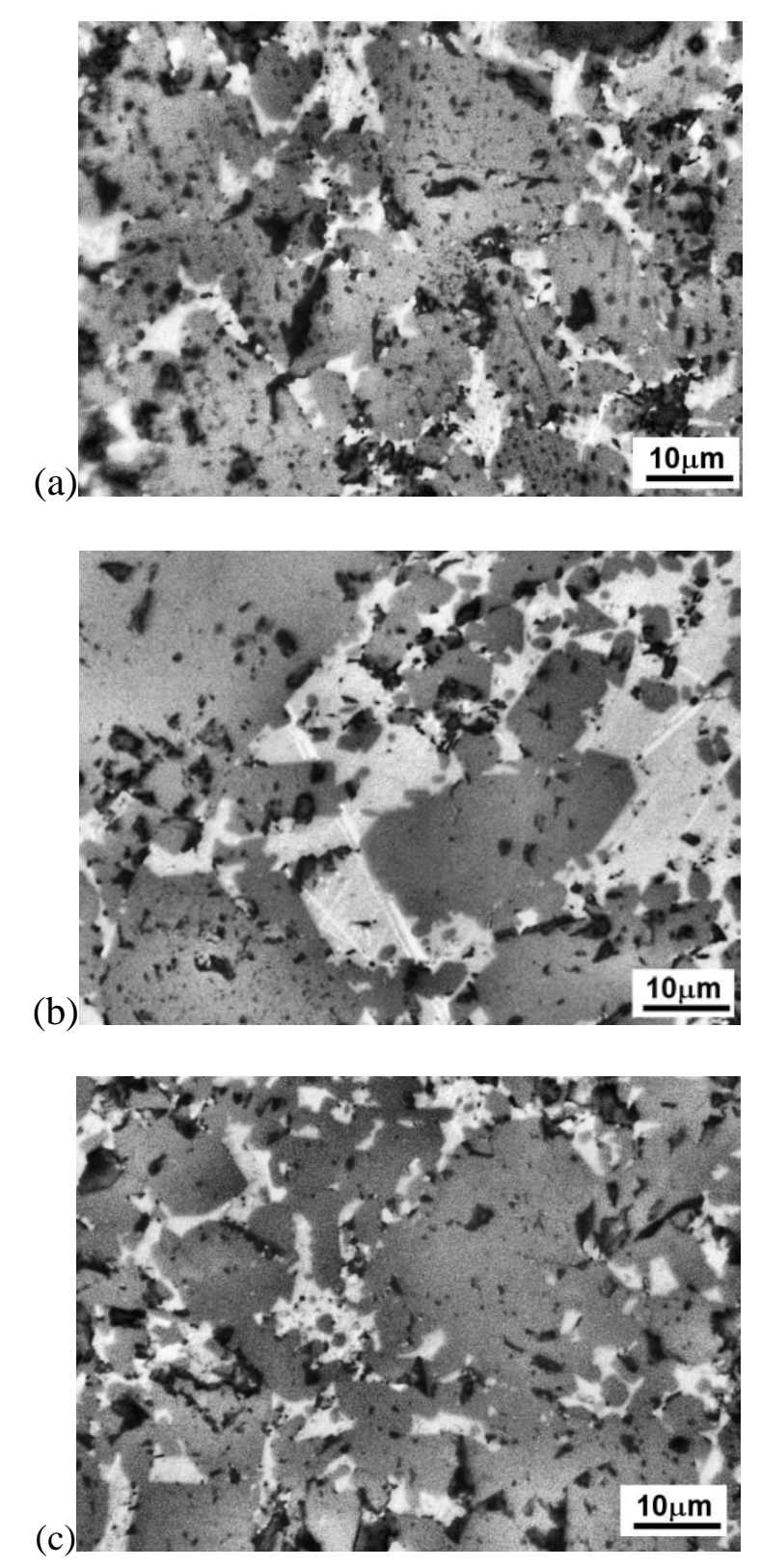

Fig. 8. Topology of surface polished by $65 \mu \mathrm{m}$ SiC abrasives ( $200 \mathrm{~mm}$ diameter disk, $30 \mathrm{rpm}$ rotational speed and $20 \mathrm{~N}$ loading force): (a) Grooves on $\mathrm{SiC}$ grain surface of the sample polished after 5 minutes $(\mathrm{Ra}=0.79 \mu \mathrm{m}$ ), (b) Discontinuity of grooves on SiC grain surface of the sample polished after 10 minutes $(\mathrm{Ra}=0.60 \mu \mathrm{m})$, (c) Disappearance of groves on the sample polished after 15 minutes $(\mathrm{Ra}=0.57 \mu \mathrm{m})$.

In contrast with the surfaces processed by diamond disk where large-scale brittle pits were formed in almost all the SiC grain surfaces, only a small fraction of brittle pits was found in the surface processed by SiC abrasives. Brittle fractures have been noticed at the edges of the SiC grains adjacent to the Si matrix. There was no obvious deposition of the deformed Si on the processed $\mathrm{SiC}$ area. It is interesting to find that grooves aligned with the abrasive motion 
on the $\mathrm{SiC}$ grain surface were formed, particularly when the processing time was short (Fig. 8(a)). It is noted that whereas deep groves were formed on the surface of the Si matrix, the grooves on the $\mathrm{SiC}$ grains were shallow. The appearance of grooves on the $\mathrm{SiC}$ surface as well as its disappearance when the process time was increased indicates that such hard and brittle material was undergone a transition from brittle to ductile removal mode [26].

The capability of SiC abrasives to engage into the sample material and initiate the material removal process can be explained as follows. With a same force applied, a SiC abrasive was unable to penetrate into the $\mathrm{SiC}$ grains as deep as from a diamond abrasive. The abrasive was either broken into smaller fragments or worn out. However, the lower hardness on the Si matrix allowed the abrasive tip to penetrate deeper into its surface, as illustrated in Fig. 9(a). During the process, the motion of the penetrated tip was disrupted upon the contact with the edges of the SiC grains. Depending on the sharpness of the abrasive, the tip could rub against the $\mathrm{SiC}$ grain surface without material removal or generated on the $\mathrm{SiC}$ grain surface a shallow groove.

The smooth surface induced by a brittle-ductile transition in the processing material can be explained as follows. Firstly, it was due to the small engagement (indent) depth. In a topical review in the diamond machining of $\mathrm{SiC}$ [25], it was stated that almost any material, including super-hard substances like diamond and $\mathrm{SiC}$, can be deformed plastically. However, this can only occur at a very small length scale during the contact loading, such as nano-impact, nano-indentation or nano-metric cutting. According to the model proposed by researchers $[27,28]$, it is suggested that the brittle-ductile transition in the chip removal process of brittle materials is a result of two processes; one is due to a plastic deformation on the slip plane and the other is due to a cleavage fracture on the cleavage plane. A plastic 
deformation occurs in front of cutting edge when the resolved shear stress in the easy slip direction exceeds a certain critical value inherent to the work material before a cleavage takes place. At a larger indent depth, the critical stress field initiates nuclei for crack propagation, forming the defects of brittle removal mode. On the contrary, with a smaller indent depth, the resulting critical stress field is small enough to avoid cleavage initiated at the defects, resulting in a ductile removal mode. Secondly, other essential factors that determine machining mode in the material include cutting speed and tool geometry. Experiments conducted by researchers [5] using a single point diamond tool have shown that the tendency of ductile removal mode in SiC occurred likely when using a negative rake tool and a small feed rate. With a small feed rate, according to [26], the energy required to propagate a crack is greater than that for plastic yielding, thus prevailing a plastic response within brittle materials. Whereas by using a negative rake-angled tool, a hydrostatic stress state is exerted in the workpiece, which inhibits the crack propagation and promote a brittle response from brittle materials [27].

In an abrasive wear process, an abrasive particle may be considered to scratch a hard $\mathrm{SiC}$ surface with an indented depth of $d_{i n}$ and a linear speed of $v$. From the aforementioned analysis, the portion of the hard phase SiC that can be processed under a ductile mode, $p(\operatorname{SiC})_{\text {duct }}$, can be expressed as

$$
p(\operatorname{SiC})_{d u c t} \sim\left(\frac{1}{d_{\text {in }}}, \frac{1}{v}, \lambda\right)
$$

where $p(\mathrm{SiC})_{\text {duct }}$ has a value from 0 to 1 , where 0 stands for a fully brittle fracture mode and 1 is for a fully ductile deformation model, $\lambda$ is a geometrical factor to account the effect of the shape of indented particle, i.e.

$$
\lambda=\lambda(n, \bar{\gamma}, A)
$$


in which $n$ is the number of the active cutting edges on the indented particle, $\bar{\gamma}$ is the average rake angle formed by the cutting edges, and $A$ is the tip contact area.

For diamond disk polishing of $\mathrm{SiC}$, it is reasonable to assume that the wear of diamond abrasives was negligible, so that the indented depth, $d_{i n}$, remains unchanged. For given material properties, Young's moduli, Poisson's ratios and harnesses of the abrasive and target materials $[29,30]$, the indented depth, $d_{i n}$, depends solely on the load, $P$, applied (i.e. $20 N$ in this study). Under the given processing condition, the removal of the $\mathrm{SiC}$ material is dominated by the brittle mode. In contrast, when polishing with SiC abrasives, the wear of SiC abrasive was significant. At the beginning, with a small tip, it allows an abrasive to penetrate deeply into the Si phase which consequently engages with the nearby SiC grains at a larger $d_{i n}$, resulting in a dominant brittle fracture mode. However, the progressive wear of SiC abrasives with processing time, $t$, changes the shape of the abrasives, $\lambda$, which flattens the tips of the abrasives and gives rise to the negative rake angle, as illustrated in Fig. 9(b), as can be expressed by

$$
\text { and } \begin{aligned}
\frac{\partial A}{\partial t} & >0 \\
\frac{\partial|\gamma|}{\partial t} & >0
\end{aligned}
$$

These changes restrict the penetration from going deeper, resulting in

$$
\frac{d\left(d_{\text {in }}\right)}{d t}<0
$$

This in turn increases the portion of $\mathrm{SiC}$ that can be processed under the ductile mode $p(\operatorname{SiC})_{\text {duct }}$. Consequently, the assemblage of the numerous micro/nano-grooves created under the ductile mode by a number of polishing abrasives gradually removes the brittle pits created at the initial stage of the process, resulting in a smooth surface (Figs. 8(b) and 8(c)). 
The enlargement of the contact area between abrasive tip and work material lowers the penetration depth. Whereas this promotes the ductile removal mode in the material, it is also a main cause for the ineffectiveness of operation at a certain stage of the process. When the width of the flattened tips is increased to about the width of the Si matrix gap, the edges of the tips are not able to engage with the SiC grains to perform the material removal action. Polishing beyond this stage has no significant effect on the surface finish.

The use of SiC abrasives enables mirror finish to be achieved on the RB-SiC surfaces. There is a threshold value of the abrasive dullness caused by its progressive wear in relation to the gap of Si matrix, beyond which material removal is minimum. By controlling the process parameters according to the wear rate of $\mathrm{SiC}$ abrasives to suit the different material compositions, it is possible to obtain the polished surface where the ductile removal mode is dominant. A combined use of diamond and SiC abrasives may be an effective method to achieve a good or even mirror surface finish.

(a)

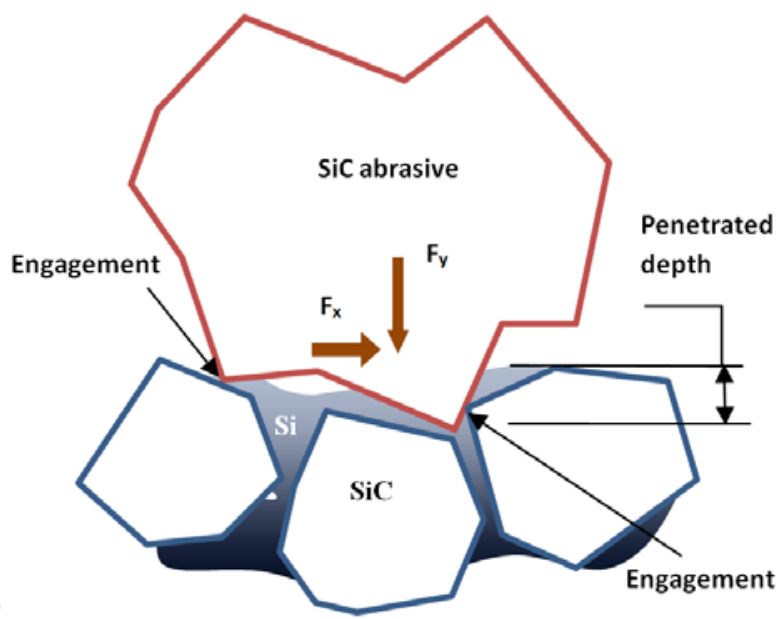

(Fig. 9 Continued) 


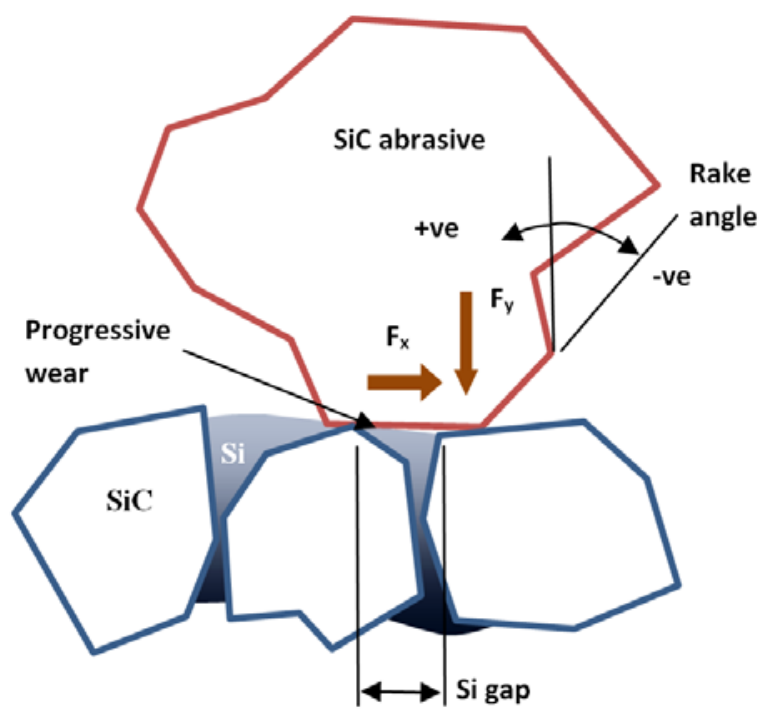

Fig. 9. Wear mechanisms of RB-SiC in SiC disk polishing: (a) Engagement of abrasive tip into the Si matrix, and (b) Progressive wear on SiC abrasive, preventing its penetration into the Si matrix.

\subsection{Wear mechanisms by the impact of particle laden water jet}

Fig. 10 illustrates the topology and 3D profile of the surfaces processed after 10 seconds by a slurry jet containing $25 \mu \mathrm{m}$ alumina particles at $20 \%$ concentration on RB-SiC. In this work, the jet pressure was $25 \mathrm{MPa}$, lower than the hydrostatic pressure that can initiate phase transformation for the Si matrix, and the hardness of the alumina particles used was lower than that of the SiC grain constituent. In spite of these facts, wear has taken place, forming a hole with a depth of about $141 \mu \mathrm{m}$ which is about four times of the average $\mathrm{SiC}$ grain size $(\approx$ $35 \mu m$ as shown in Fig. 1). The processed surface appeared with irregular patterns of exposed $\mathrm{SiC}$ grains. Surface roughness measured at the bottom of the hole within the impact area was $R_{a}=24.6 \mu \mathrm{m}$ which is within the range $\left(0.5 d_{S i C}, d_{S i C}\right)$, in which $d_{S i C}$ is the average size of SiC grains. Channels were formed on the Si matrix surrounding the exposed SiC grains. For a comparison purpose, Fig. 11 shows an eroded surface on the Si wafer. A hole of about 228 $\mu m$ in depth was formed and the processed surface was smoother than on the RB-SiC, as shown in Fig. 12. On the eroded crater wall, there are a number of waves arranged 
concentrically. It may be noted that although both are brittle materials, no micro cracks were found on eroded surfaces of the samples.

(a)

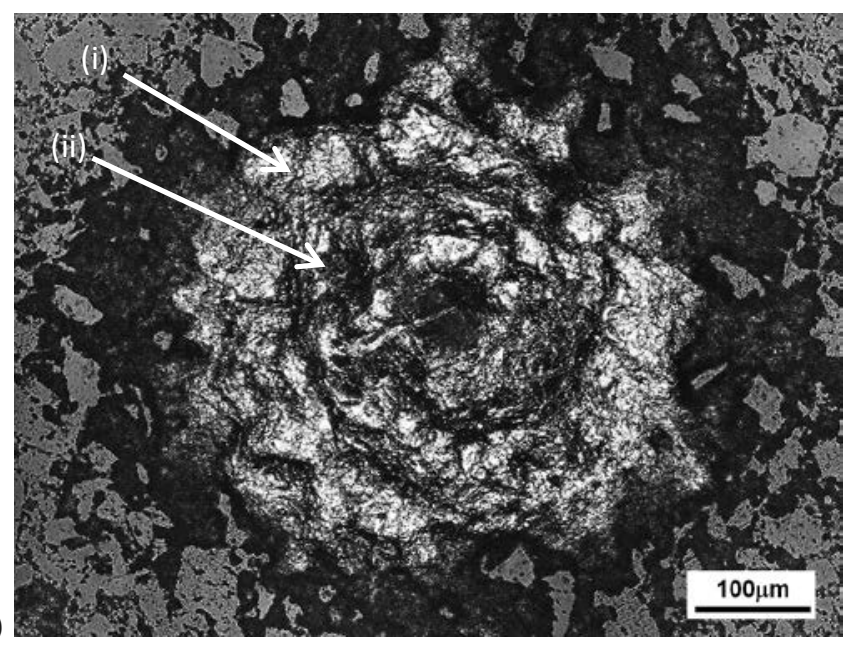

(b)

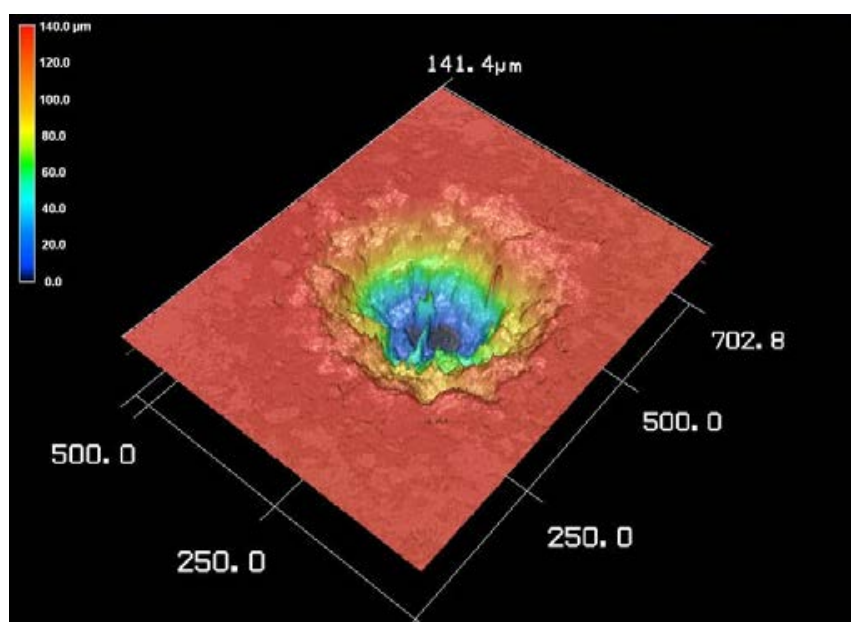

Fig. 10. Topology (a) and 3D profile (b) of surfaces processed after 10 seconds by a 0.125 $\mathrm{mm}$ diameter slurry jet containing $25 \mu \mathrm{m}$ alumina particles with the concentration of $15 \%$ by mass and at $25 \mathrm{MPa}$ on RB-SiC ((i) exposed SiC grains and (ii) channels). 

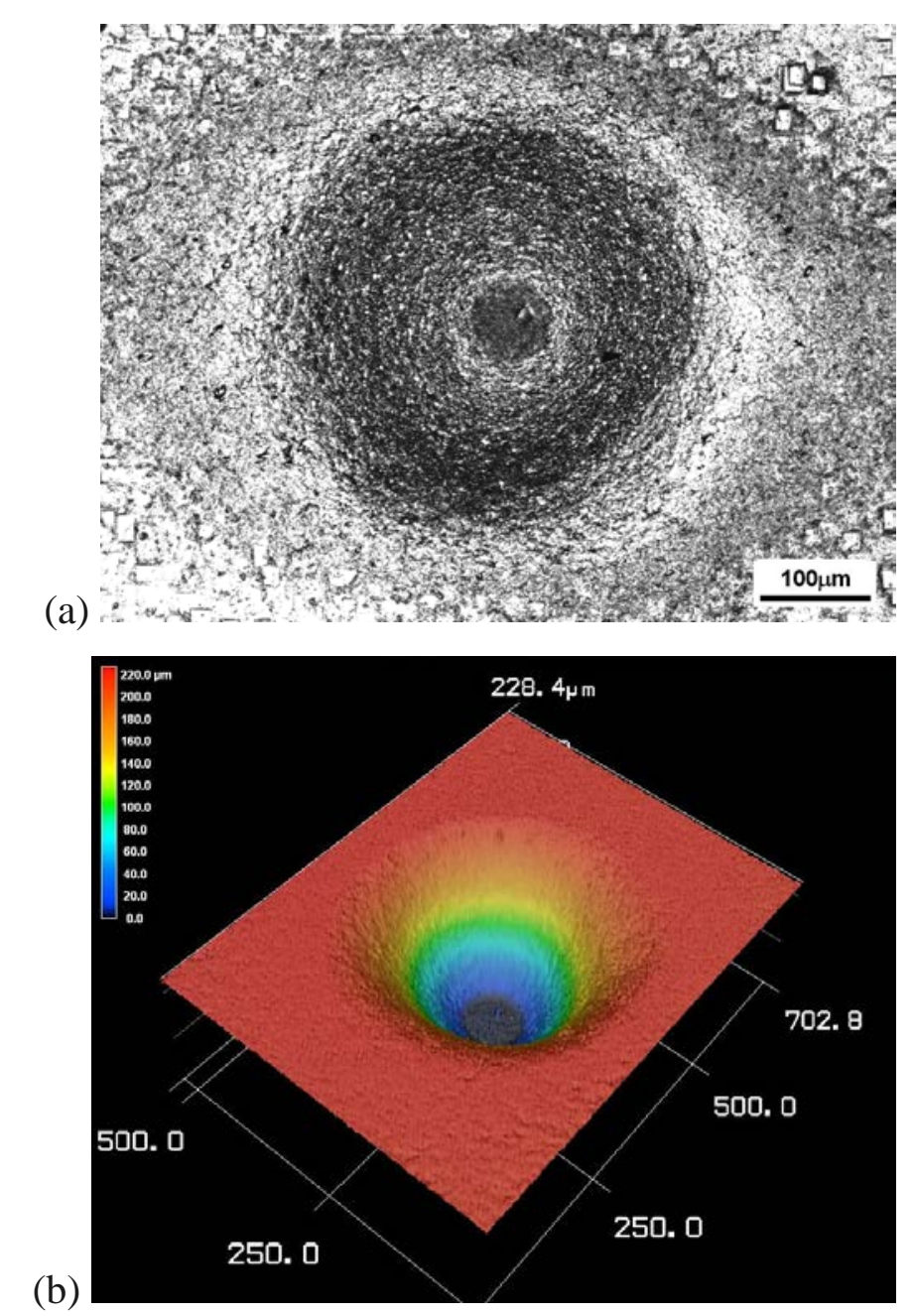

Fig. 11. Topology (a) and 3D profile (b) of surfaces processed after 10 seconds by a 0.125 $\mathrm{mm}$ diameter slurry jet containing $25 \mu \mathrm{m}$ alumina abrasives with the concentration of $15 \%$ by mass and at $25 \mathrm{MPa}$ on Si wafer.

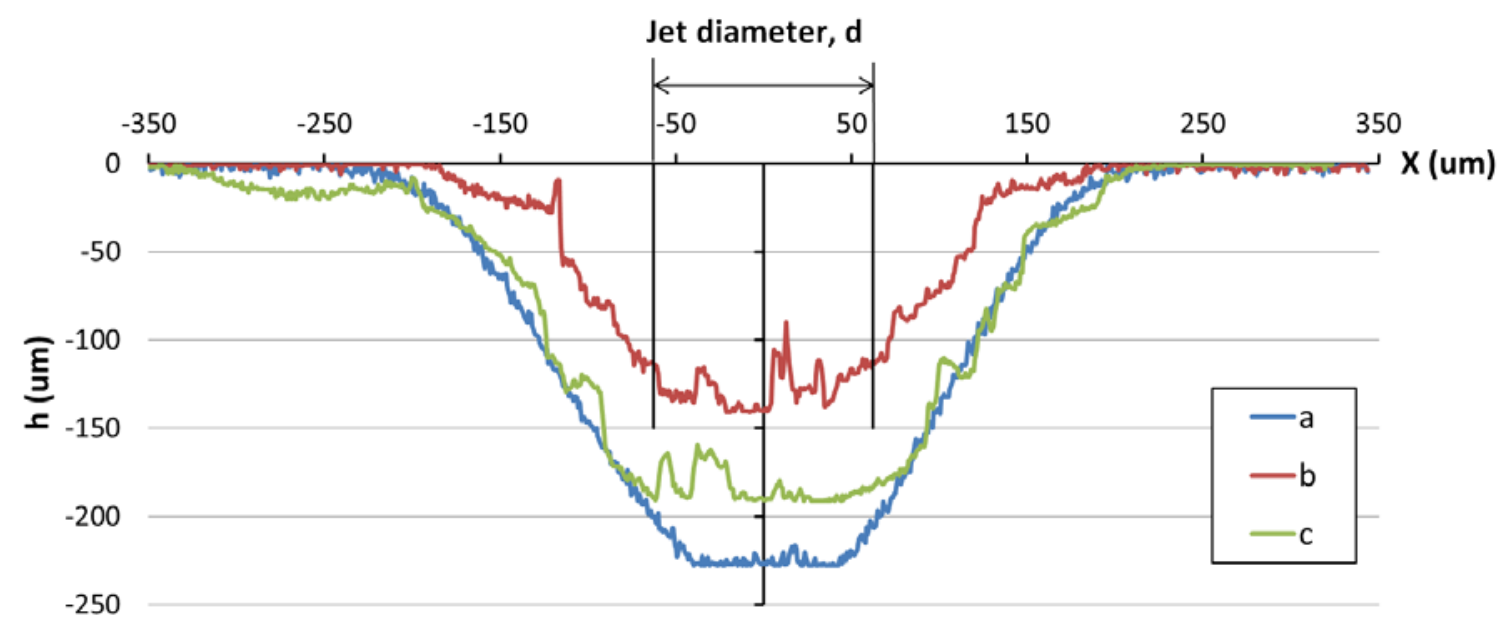

Fig. 12. Cross sectional profile of holes processed after 10 seconds by a $0.125 \mathrm{~mm}$ diameter slurry jet containing $25 \mu \mathrm{m}$ abrasives with the concentration of $15 \%$ by mass and at $25 \mathrm{MPa}$ pressure: (a) alumina abrasives on Si wafer, (b) alumina abrasives on $\mathrm{RB}-\mathrm{SiC}$ and (c) $\mathrm{SiC}$ abrasives on RB-SiC. 
The characteristics on the processed surface of Si wafer can be explained as a result of different wear processes associated with the change of flow regimes developed on the surface $[11,31]$. Upon the impact of a jet on a brittle material, the normal force facilitates an indentation [32]. Since the stand-off distance set in this study was small, the effect of the stagnation in the jet impact was small. Such an indentation therefore immediately eroded the impact material to form a crater, at the bottom of which was a relatively flat surface. As the flow continued, some particles were splashed out [33], and the remaining particles were diverged and formed a secondary viscous flow that swept outward the impact area. It is noted that the normal force component of this diverged flow is lower than that of the impinging flow within the impact zone. However, since the abrasives contained in the flow are harder than the target material, $\mathrm{Si}$, the normal force component was able to initiate a penetration into the material surface, though at a lower degree of magnitude. Owing to the "flexibility" of its liquid form, the jet allowed the abrasives to roll, collide and move freely. Wear took place mainly by a shearing action caused by the motion of rolled abrasives. The disturbance of liquid film resulted from a pressure fluctuation near the free surface of turbulence flow in this flow regime [34-36] generated the wavy pattern on the surface.

The wear mechanism of RB-SiC is clearly different from that of the single-phase Si. Unlike impacting on a Si wafer, the alumina abrasives, particularly when driven by a low pressured jet, cannot penetrate into the harder $\mathrm{SiC}$ grains of $\mathrm{RB}-\mathrm{SiC}$ to initiate an indentation. Upon an impact on SiC grains, the abrasives were rebounded, broken and/or collided with other abrasives, so that the engagement was made only by the particles impacting on the Si matrix whose hardness is lower than that of the abrasives. The removal of material was then followed by two actions that processed simultaneously: shearing and wedging. Following the 
engagement, the rolling of the engaged abrasives promoted a shearing stress to erode the $\mathrm{Si}$ surface. As a result, a number of channels along the Si matrix and around the harder SiC grains were formed, as illustrated in Figs. 11 and 13. Irrespective of the fact that there was no wear made directly on the SiC grains, the depth of the hole processed in this test was about four times the SiC grain size. It is implied that the removal of the $\mathrm{SiC}$ grains was made via the weakening of their bonding to the material structure, so that the whole grains were removed from the substrate. On the other hand, it is noted that since the volume fraction of Si is small ( $C_{S i} \approx 21.5 \%$ ), the portion of the Si surface that can be exposed to the jet was small. In addition, the space between the hard SiC grains is not uniformly arranged within the material structure, and in many locations, the space is much smaller than the abrasive size (Fig. 1). As the process continued, the channels were expanded wider and deeper. However, the narrow space between the SiC grains prevented the abrasives from penetrating to the roots of the SiC grains, to allow their cutting edges to promote a shearing action. In such narrowspaced locations, indentation of the coming abrasives promoted a wedging action to lift up the grains, as illustrated in Fig. 13. Micro-cracks might be formed as a result of the wedging action. However, the motion of the rolling abrasives over the newly cracked surface "smoothened" the cracks, and removed the residual Si bonding from the exposed surface of the SiC grains, resulting in the surface topology shown in Fig. 10. Outward the impact zone, the disturbance of the liquid film developed from the viscous flow was also formed. However, the flow was disrupted when hitting the SiC grains without causing any notable wear. 
(a)

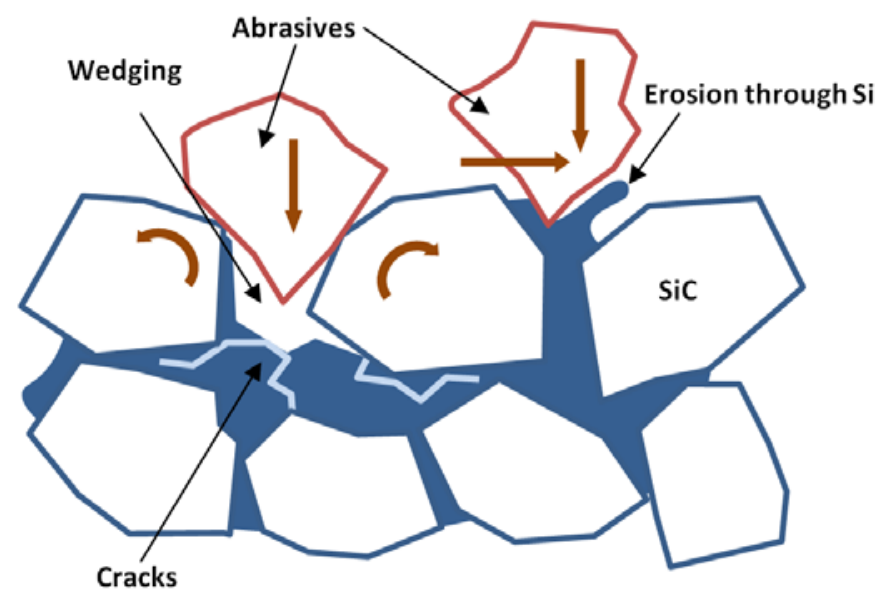

(b)

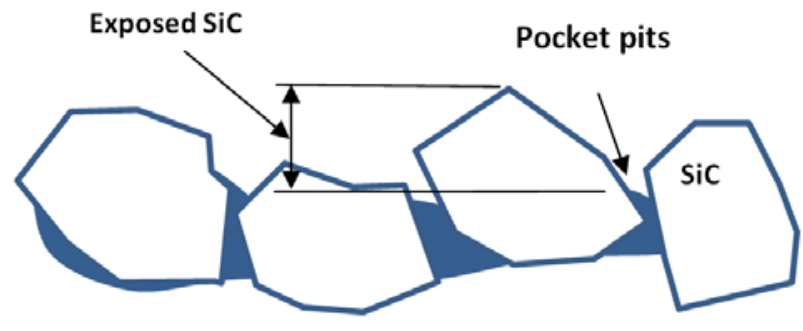

Fig. 13. Wear mechanisms of RB-SiC by an alumina slurry jet: (a) Material removal, and (b) Exposed surface.

Fig. 14 shows a hole produced under a same processing condition as that using the alumina abrasives for RB-SiC, but with harder SiC abrasives. This hardness allowed the sharpness of abrasives to be retained during the process, resulting in a deeper hole (193 $\mu \mathrm{m}$ vs $141 \mu \mathrm{m})$, as shown in Fig. 12. However, there was no significant change of the surface appearance, i.e. all eroded surfaces were characterised by a number of exposed SiC grains and channels that run around the grains, and the surface roughness was $R_{a}=23.9 \mu \mathrm{m}$ (vs $24.6 \mu \mathrm{m}$ obtained from that processed by alumina abrasives). It is interesting to compare the results with that obtained by the $\mathrm{SiC}$ disk polishing tests described in Section 3.2. In that test, there was an actual interaction between the $\mathrm{SiC}$ abrasives and the $\mathrm{SiC}$ grains to smoothen the grains as well as causing a progressive wear that flattened the tips of abrasives. In the case of using a slurry jet, in spite of new sharp-edged abrasives were continuously introduced, the RB-SiC surface was mainly processed through the softer Si phase, as discussed earlier. It is noted that 
the abrasives hitting the harder SiC grains tend to move to the softer Si phase nearby to erode the softer phase.

Figure 14 shows the surface topology of the holes processed with the $\mathrm{SiC}$ and alumina abrasives, but at lower pressure of $20 \mathrm{MPa}$ and shorter processing time of 5 seconds. Surface roughness measured at the bottom of the holes was $25.79 \mu \mathrm{m}$ and $24.51 \mu \mathrm{m}$, respectively. The change of processing parameters altered the volume of material removed. However, it appears that the roughness obtained is not influenced significantly by the operating pressure, abrasive hardness and processing time.

(a)

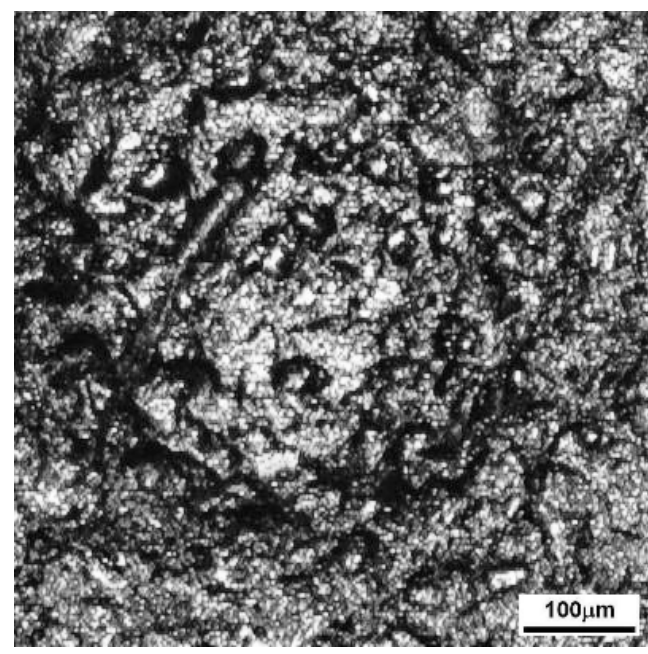

(b)

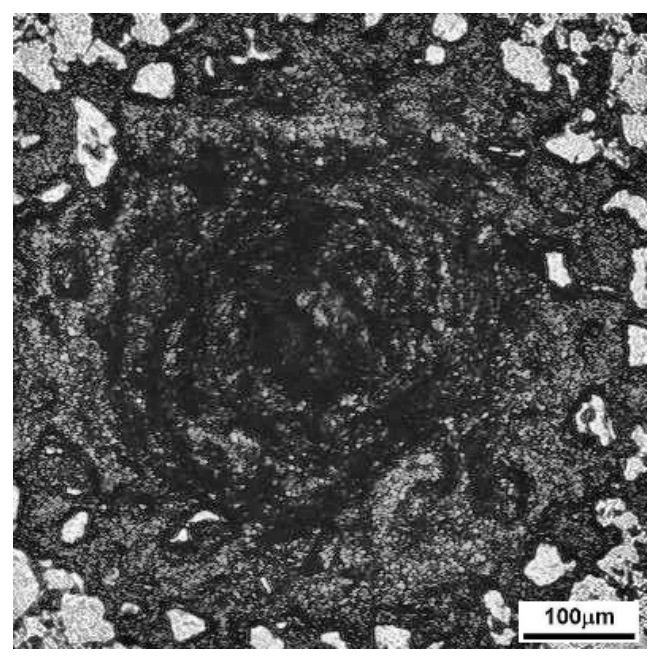

Fig. 14. Topology of surfaces processed after 5 seconds by a $0.125 \mathrm{~mm}$ diameter jet of slurry at a $20 \mathrm{MPa}$ pressure with the concentration of $15 \%$ by mass: (a) $25 \mu \mathrm{m}$ alumina particles and (b) $25 \mu \mathrm{m} \mathrm{SiC} \mathrm{particles.}$

It can be stated that this type of wear in fact is through a weakening process in the Si bond by erosion and wedging, which eventually releases the $\mathrm{SiC}$ grain from the material structure. The roughness of the processed surface, $R_{a}$, was determined by the number and height of the exposed $\mathrm{SiC}$ grains that were remained with the material after the process. It can be expressed as

$$
R_{a}=R_{a}\left(d_{p} / d_{S i C}, C_{S i C}, E_{S i}\right)
$$


where $d_{S i C}$ is the avergae size of SiC grains; $d_{p} / d_{S i C}$ represents the relative size of abrasive particles to that of SiC grains; $C_{S i C}\left(=1-C_{S i}\right)$ is the volumetric fraction of the $\mathrm{SiC}$ grains in the material structure; and $E_{S i}$ is the bonding energy of the Si bonding which is influenced by the fabrication process of material. Both parameters $d_{p} / d_{S i C}$ and $C_{S i C}$ determine the maximum depth of an abrasive that can erode into the Si matrix to promote the wedging action.

The presence of Si matrix has a detrimental effect on the strength and wear resistance of RBSiC. A component made from RB-SiC can fail below the expectations when subjecting to this type of wear. On the other hand, it is possible to use a relatively low-pressure alumina slurry jet to machine RB-SiC and the processed surface quality depends mainly on the material structure.

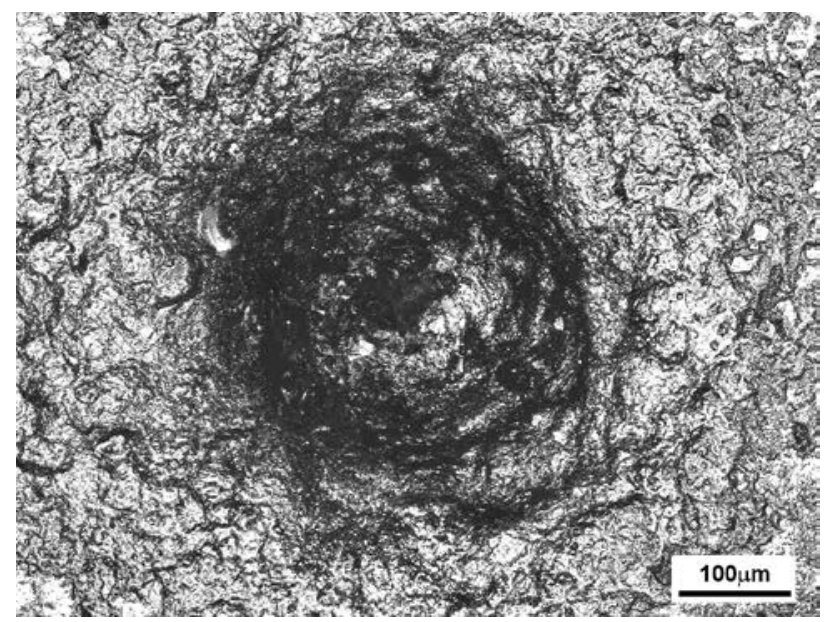

(Fig. 14 continued) 


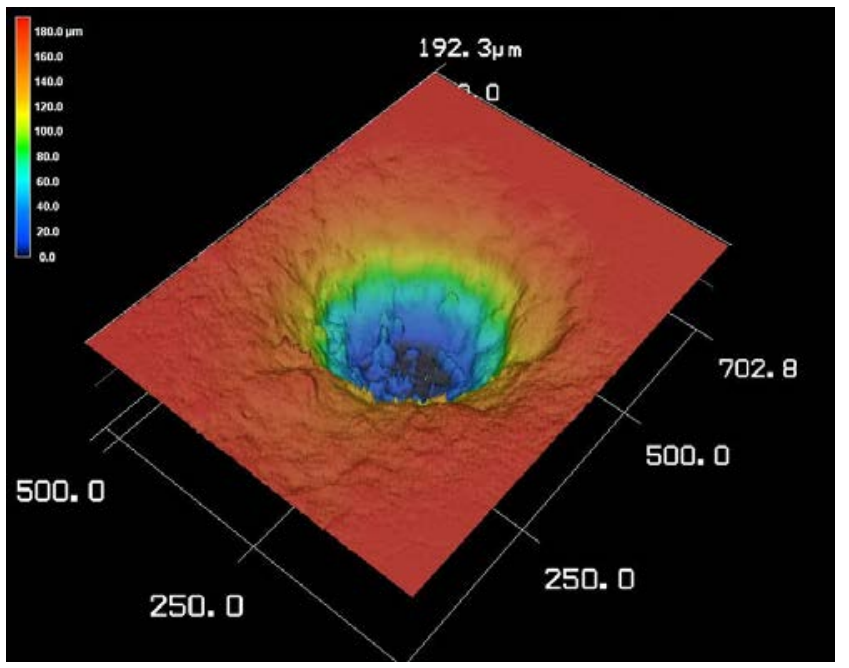

Fig. 14. Topology (a) and 3D profile (b) of surfaces processed after 10 seconds by a 0.125 $\mathrm{mm}$ diameter slurry jet containing $25 \mu \mathrm{m} \mathrm{SiC}$ abrasives with the concentration of $15 \%$ by mass and at a $25 \mathrm{MPa}$ pressure on RB-SiC.

\section{Conclusions}

The study has provided an insight into the abrasive wear mechanisms of the two-phased material, RB-SiC. The abrasive wear on RB-SiC involves different mechanisms in the Si and SiC constituents. The wear process depends on the abrasive hardness and the method in which the abrasives are applied to the material surface. In diamond disk polishing, brittle fracture mode is dominant on the SiC phase. There are depositions of the plastically deformed Si phase on the fractured SiC surface. By contrast, in SiC disk polishing, submicrometer surface finish can be obtained. The removal of material is initiated by the engagement of abrasives into the softer Si matrix. It has been found that a low-pressured alumina slurry jet can cause wear on RB-SiC through the removal of softer Si bond and release of the SiC grains from the material structure. The presence of the Si phase has a detrimental effect on the strength and wear resistance of RB-SiC. It is feasible to use a relatively low-pressure alumina slurry jet to machine RB-SiC without causing any brittle surface damage and the processed surface quality depends mainly on the material structure. 
This work has provided a basis for further studies to quantitatively analysing and determining the surface integrity and material removal rate in relevant processes.

\section{Acknowledgement}

The project was financially supported by the Australian Research Council (ARC) under the Discovery-Projects scheme.

\section{References}

1. U. Paik, H.C. Park, S.C. Choi, C.G. Ha, J.W. Kim, and Y.G. Jung, Effect of particle dispersion on microstructure and strength of reaction-bonded silicon carbide, Mat Sci Eng. 334(1-2) (2002) 267-274. http://dx.doi.org/10.1016/S0921-5093(01)01897-4.

2. J.N. Ness and T.F. Page, Microstructural evolution in reaction-bonded silicon carbide, J Mater Sci. 21(4) (1986) 1377-1397. https://doi.org/10.1007/BF00553278.

3. H. Suyama, Y. Itoh, K. Tsuno, and K. Ohno. NT-SiC (new-technology silicon carbide) : $\Phi 650 \mathrm{~mm}$ optical space mirror substrate of high-strength reaction-sintered silicon carbide. in Proc. SPIE, Optical Materials and Structures Technologies II. (2005) 5868E. http://dx.doi.org/10.1117/12.616043

4. Y. Toulemont, J. Breysse, D. Piepot, and S. Miura. The 3.5m all SiC Telescope for SPICA. in Proc. SPIE 5487, 1001-1012. (2004). https://doi.org/10.1117/12.551405

5. J. Patten, W. Gao, and K. Yasuto, Ductile Regime Nanomachining of Single-Crystal Silicon Carbide, J Manuf Sci Eng. 127(3) (2004) 522-532. http://dx.doi.org/10.1115/1.1949614.

6. M. Budnitzki and M. Kuna, Stress induced phase transitions in silicon, J Mech Phys Solids. 95 (2016) 64-91. http://dx.doi.org/10.1016/j.jmps.2016.03.017.

7. K. Yamamura, Y. Yamamoto, and H. Deng, Preliminary study on chemical figuring and finishing of sintered SiC substrate using atmospheric pressure plasma, Procedia CIRP. 3 (2012) 335 - 339. https://doi.org/10.1016/j.procir.2012.07.058. 
8. X. Shen, Q. Tu, H. Deng, G. Jiang, and K. Yamamura. Mechanism analysis on finishing of reaction-sintered silicon carbide by combination of water vapor plasma oxidation and ceria slurry polishing. in Optical Engineering, SPIE. 54(5) (2015) 055106: SPIE. https://doi.org/10.1117/1.OE.54.5.055106

9. N. Shimozono, X. Shen, H. Deng, K. Endo, and K. Yamamura, Figuring and finishing of reaction-sintered SiC by anodic oxidation assisted process, Key Eng Mater. 625 (2015) 570-575. https://doi.org/10.4028/www.scientific.net/KEM.625.570.

10. H. Liu, J. Wang, and C.Z. Huang, Abrasive liquid jet as a flexible polishing tool, Int J Mater Prod Tec. 31(1) (2008) 2-13. https://doi.org/10.1504/IJMPT.2008.015884.

11. J. Wang, T. Nguyen, and K. Pang, Mechanisms of microhole formation on glasses by an abrasive slurry jet, J Appl Phys. 105 (2009) 044906. http://doi/10.1063/1.3079802.

12. H.T. Zhu, C.Z. Huang, J. Wang, Q.L. Li, and C.L. Che, Experimental study on abrasive waterjet polishing for hard-brittle materials, Int J Mach Tool Manu. 49(7) (2009) 569-578. http://dx.doi.org/10.1016/j.ijmachtools.2009.02.005.

13. Y. Zhang, J. Zhang, J. Han, X. He, and W. Yao, Large-scale fabrication of lightweight Si/SiC ceramic composite optical mirror, Mater Lett. 58(7) (2004) 1204-1208. https://doi.org/10.1016/j.matlet.2003.09.010.

14. F. Cheng, S. Zhang, Q. Zhao, and L. Zhang. Study on Indentation Experiments and Mechanical Behavior of RB-SiC. in MATEC Web Conf. International Conference on Electronic Information Technology and Computer Engineering (EITCE 2017). 128((2017) 03010. http://doi.org/10.1051/matecconf/201712803010

15. C. Yang and J. Pham, On the Fracture Toughness Measurement of Thin Film Coated Silicon Wafers, Silicon. 7(1) (2015) 27-30. https://doi.org/10.1007/s12633-014-9215$\underline{1 .}$

16. A. Tucci and L. Esposito, Microstructure and tribological properties of $\mathrm{ZrO} 2$ ceramics, Wear. 172(2) (1994) 111-119. https://doi.org/10.1016/00431648(94)90278-X. 
17. M.J. McCarthy and N.A. Molloy, Review of stability of liquid jets and the influence of nozzle design, Chem Eng. 7(1) (1974) 7-20. https://doi.org/10.1016/0300$\underline{9467(74) 80021-3 .}$

18. T. Nguyen, D.K. Shanmugam, and J. Wang, Effect of liquid properties on the stability of an abrasive waterjet, Int J Mach Tool Manu. 48 (2008) 1138-1147. https://doi.org/10.1016/j.ijmachtools.2008.01.009.

19. D. Tabor, The hardness of solids, Rev Phys Tech. 1(3) 145-179. https://doi.org/10.1088/0034-6683/1/3/I01.

20. J. Yan, Z. Zhang, and T. Kuriyagawa, Mechanism for material removal in diamond turning of reaction-bonded silicon carbide, Int J Mach Tool Manu. 49(5) (2009) 366374. http://dx.doi.org/10.1016/j.ijmachtools.2008.12.007.

21. M. Yoshida, A. Onodera, M. Ueno, K. Takemura, and O. Shimomura, Pressureinduced phase transition in SiC, Phys Rev B. 48(14) (1993) 10587-10590. http://dx.doi.org/10.1103/PhysRevB.48.10587.

22. S. Agarwal and P.V. Rao, Experimental investigation of surface/subsurface damage formation and material removal mechanisms in SiC grinding, Int J Mach Tool Manu. 48(6) (2008) 698-710. https://doi.org/10.1016/j.ijmachtools.2007.10.013.

23. I. Zarudi, T. Nguyen, and L.C. Zhang, Effect of temperature and stress on plastic deformation in monocrystalline silicon induced by scratching, Appl Phys Lett. 86 (2005) Paper No. 011922. https://doi.org/10.1063/1.1847692.

24. J. Jang, M.J. Lance, S. Wen, T.Y. Tsui, and G.M. Pharr, Indentation-induced phase transformations in silicon: influences of load, rate and indenter angle on the transformation behavior, Acta Mater. 53(6) (2005) 1759-1770. http://dx.doi.org/10.1016/j.actamat.2004.12.025.

25. G. Saurav, The current understanding on the diamond machining of silicon carbide, J Phys D: Appl Phys. 47(24) (2014) 243001. http://stacks.iop.org/0022$\underline{3727 / 47 / \mathrm{i}=24 / \mathrm{a}=243001}$. 
26. T. Bifano, T. Dow, and R. Scattergood, Ductile-Regime Grinding: A New Technology for Machining Brittle Materials, ASME J Eng Ind. 113(2) (1991) 184189. http://doi.org/:10.1115/1.2899676.

27. T. Nakasuji, S. Kodera, S. Hara, H. Matsunaga, N. Ikawa, and S. Shimada, Diamond Turning of Brittle Materials for Optical Components, CIRP Annals. 39(1) (1990) 8992. https://doi.org/10.1016/S0007-8506(07)61009-9.

28. S. Shimada, N. Ikawa, T. Inamura, N. Takezawa, H. Ohmori, and T. Sata, BrittleDuctile Transition Phenomena in Microindentation and Micromachining, CIRP Annals. 44(1) (1995) 523-526. https://doi.org/10.1016/S0007-8506(07)62377-4.

29. J. Malzbender and G. de With, Indentation load-displacement curve, plastic deformation, and energy, J Mater Res. 17(2) (2002) 502-511. https://doi.org/10.1557/JMR.2002.0070.

30. A.V. Gopal and P.V. Rao, A new chip-thickness model for performance assessment of silicon carbide grinding, Int J Adv Manuf Tech. 24(11) (2004) 816-820. https://doi.org/10.1007/s00170-003-1788-6.

31. T. Nguyen, K. Pang, and J. Wang, A Preliminary study of the erosion process in micro-machining of glasses with a low pressure slurry jet, Key Eng Mater. 389-390 (2009) 375-380. http://dx.doi.org/10.4028/www.scientific.net/KEM.389-390.375.

32. M.C. Rochester and B. J.H. High speed impact of liquid jets on solids. in 1st International Symposium on Jet Cutting Technology. (1972) University of Warwick, Conventry, England.

33. S.K. Bhunia and V.J.H. Lienhard, Spattering during turbulent liquid jet impingement on solid targets, J Fluids Eng Trans ASME. 116(2) (1994) 338-344. http://doi:10.1115/1.2910277.

34. R.H. McLean, Crossflow and impact under jet bits, J Petrol Tech. 16(11) (1964) 1299-1306. https://doi.org/10.2118/889-PA. 
35. X. Liu and J.H. Lienhard, The hydraulic jump in circular jet impingement and in other thin liquid films, Exp Fluids. 15(2) (1993) 108-116. https://doi.org/10.1007/bf00190950.

36. S.K. Bhunia and V.J.H. Lienhard, Surface Disturbance Evolution and the Splattering of Turbulent Liquid Jets, J Fluid Eng. 116(4) (1994) 721-727. http://doi.org/10.1115/1.2911841. 